\title{
CONHECIMENTO DOS ADOLESCENTES SOBRE MÉTODOS CONTRACEPTIVOS E ASSISTÊNCIA EM SAÚDE
}

\author{
KNOWLEDGE OF ADOLESCENTS ABOUT CONTRACEPTIVE \\ METHODS AND HEALTH CARE
}

\author{
Larissa Soares Mariz Vilar de Miranda ${ }^{1}$
}

Eliene Maria de Souza ${ }^{2}$

\begin{abstract}
RESUMO: É notável o aparecimento de adolescentes que se contaminam por ISTs e engravidam nas primeiras relações sexuais havendo necessidade de uma atenção básica de saúde voltado para essa faixa etária. OBJETIVO: investigar o conhecimento sobre saúde sexual, métodos contraceptivos e assistência em saúde em adolescentes da rede pública de educação do município de Caturité-PB. MÉTODOS: Estudo de caráter exploratório, descritivo e com abordagem quantitativa, realizada nas escolas municipal, com adolescentes de 10 a 19 anos de idade e nas Estratégias, no município de Caturité-PB. Foram utilizados questionário semiestruturado, analisados posteriormente utilizando estatística simples. A pesquisa foi realizada entre Setembro e Outubro de 2018 e respeitou os critérios éticos. RESULTADOS: Os adolescentes possuem conhecimento sobre métodos contraceptivos, mas de forma errônea o que pode levar a contrair ISTs ou gravidez indesejada, por estarem iniciando sua vida sexual cada vez mais cedo e por não ter assistência e orientação de saúde adequada. CONCLUSÃO: Os adolescentes dizem conhecer os métodos mas o conhecimento não advém de profissionais de saúde. Demonstram risco aumentado para gravidez indesejada e infecções sexualmente transmissíveis. Apesar disso desejam conhecer mais sobre a temática e parecem receptivos as práticas de saúde na escola. A partir dos dados desta pesquisa as enfermeiras podem traçar metas voltadas para esse público junto com o sistema educacional, através do PSE e dentro de suas unidades de saúde buscando por uma assistência voltada para eles de forma completa, conquistando e respeitando o adolescente em seu mundo de dúvidas e angústias.
\end{abstract}

Palavras chave: Adolescente. Contracepção. Educação Sexual. Enfermagem.

\footnotetext{
${ }^{1}$ Professora Doutora do Curso Bacharelado em Enfermagem da Universidade Federal de Campina Grande - Paraíba. E-mail: larissamariz@gmail.com.

${ }^{2}$ Enfermeira graduada na Faculdade de Ciências Médicas de Campina Grande - PB.
} 
ABSTRACT: It is notable the appearance of adolescents who are contaminated by ISTs and become pregnant in the first sexual relations, with the need for primary health care geared to this age group. OBJECTIVE: to investigate knowledge about sexual health, contraceptive methods and health care in adolescents from public schools in the municipality of Caturité-PB. METHODS: An exploratory, descriptive study with a quantitative approach, carried out in municipal schools, with adolescents aged 10 to 19 years and in Strategies, in the municipality of Caturité-PB. Semistructured questionnaires were used, later analyzed using simple statistics. The research was carried out between September and October 2018 and respected the ethical criteria. RESULTS: Adolescents have knowledge about contraceptive methods, but in an erroneous way, which can lead to contracting STIs or unwanted pregnancies, because they are starting their sexual life at an earlier age and for not having adequate health care and guidance. CONCLUSION: Adolescents say they know the methods but the knowledge does not come from health professionals. Demonstrate increased risk for unwanted pregnancies and sexually transmitted infections. Despite this, they want to know more about the theme and seem receptive to health practices at school. From the data of this research, nurses can set goals aimed at this public together with the educational system, through the PSE and within their health units, seeking assistance aimed at them in a complete way, winning and respecting the adolescent in their world doubts and anxieties.

Keywords: Adolescent. Contraception .Sexual Education. Nursing. 


\section{INTRODUÇÃO}

Segundo a Organização Mundial de Saúde (BRASIL, 2003) a adolescência corresponde à faixa etária que vai e desenvolvimento onde se notam mudanças físicas, psíquicas e sociais (BRASIL, 2007).

Nesse período da vida ocorrem inúmeras mudanças físicas e psíquicas no corpo, mas os mesmos não têm conhecimento adequado sobre tais mudanças o que pode ocorrer vivencias enganosas e conflituais que poderiam ser evitadas ao receber informações simples a respeito do seu desenvolvimento (FILIPINI et al., 2013).

O início da sexualidade na vida do adolescente se dá pela necessidade do conhecimento do que é novo pra ele, e é nessa fase de rompimento com a fase da infância e passagem para vida adulta que há descobertas sem responsabilidade, deixando-o vulnerável para contrair ISTs. A falta de direcionamento por parte dos familiares e também o pouco conhecimento que esses adolescentes têm em relação à orientação sexual, isso ao longo dos anos, vem aumentando o número de jovens com ISTs e a contaminação na primeira relação. Todavia ainda existe a educação das políticaspúblicas que visam orientar os adolescentes quanto ao risco de contrair ISTs e as consequências de uma gravidez (SANTOS et al.,2017).

A gravidez na adolescência, outra consequência da falta de orientação sexual, gera mudanças sociais, físicas e emocionais com perdas de vínculos de amizades, interrupção dos estudos e afastamento de familiares, com isso essa faixa etária não se sente preparada financeiramente e emocionalmente demostrando medo e insegurança (ALVES et al.,2011).

A Estratégia e Saúde da Família (ESF) têm como responsabilidade a assistência à saúde do adolescente bem como o acesso aos métodos contraceptivos e ao planejamento familiar, contudo, pouco se percebe a frequência desses adolescentes nessas unidades, o que é presente é a real necessidade de práticas voltada para esse público com o intuito de trazê-los as unidades de saúde para 
terem acesso a esses programas e uma qualidade de vida futura melhor (RODRIGUES et al.,2017).

É possível perceber a ausência desses adolescentes nas unidades de saúde, o que, sem informação por parte dos profissionais de saúde, leva a os mesmos a fazerem uso dos métodos contraceptivos sem o conhecimento prévio de tais métodos podendo acontecer ISTs e gravidez indesejada. Mas é visto também a pouca atenção que eles dão a esses métodos como inocentemente não fossem se contaminar ou engravidar. O que também é perceptível é a contemplação só das mulheres de idade adultas no planejamento familiar quando os adolescentes também necessitam de tal planejamento e informações para sua vida sexual (RODRIGUES et al.,2017).

Assim, pode-se afirmar que a adolescência é uma fase permeada por mudanças corporais e alterações hormonais que despertam a vida sexual. Sabe-se que existe dificuldade de disseminação das informações sobre métodos contraceptivos e sexualidade entre os adolescentes, e esse fato pode levar a gravidez indesejada e contagio por ISTs. Ressalta-se a importância de educação sexual para esses adolescentes, com a intenção de futuramente terem uma vida sexual saudável, a presença de profissionais de enfermagem e de suma importância para essa faixa etária (DIAS et al., 2017).

Também é possível entender que é importante que a educação sexual seja de forma abrangente onde leve direção para família, escola e unidades de saúde, desse modo faz-se importante a presença do enfermeiro nas escolas para poder planejar e executar estratégias a fim de oferecer educação sexual e reprodutiva para esse grupo, com a intenção de prevenir ISTs e gravidez, e de formar pessoas que possam levar tais informações, envolvendo professores, pais, alunos e comunidade (ABTIBOL et al.,2015).

Devido a essa problemática e as dificuldades associadas ao déficit de assistência aos adolescentes pela Atenção Básica, e aos danos que podem causar na saúde do adolescente que perdurariam por toda vida, surgem a seguinte questão norteadora: qual o tipo de conhecimento que o adolescente possui sobre os métodos contraceptivos e que tipo de assistência à saúde é prestada a essa população? Assim, essa pesquisa teve por objetivo investigar o conhecimento sobre 
saúde sexual, métodos contraceptivos e assistência em saúde em adolescentes da rede pública de educação do município de Caturité-PB.

\section{MÉTODO}

Trata-se de uma pesquisa de caráter exploratório, experimental, descritivo com abordagem quantitativa, realizada em Setembro e Outubro de 2018. A pesquisa foi realizada, na Escola Municipal Antônio Trovão de Melo, Escola Estadual Feliz Araújo localizados no município de Caturité- Paraíba. A amostra foi composta por adolescentes na faixa etária de 10 a 19 anos. A amostra foi acidental e por conveniência, observaram-se os critérios de inclusão e exclusão. Foram incluídos 36 adolescentes do $8^{\circ}$ e $9^{\circ}$ do fundamental e $2^{\circ}$ ano médio.

Foram incluídos na pesquisa adolescentes com idade entre 10 e 19 anos, que estivessem matriculados nas escolas pesquisadas. Também foram incluídas adolescentes que no momento da coleta de dados estavam gestantes ou em pósparto. Foram excluídos alunos que estavam afastados das atividades no período de coleta de dados e faziam parte do grupo pesquisado por pelo menos três meses.

O instrumento utilizado para a coleta dos dados foi um elaborado um roteiro de entrevista semiestruturado, composto por dez questões subjetivas que abordaram as seguintes variáveis: conhecimento dos adolescentes em relação a métodos contraceptivos, iniciação da vida sexual, se conhece ou fazem uso da camisinha e anticoncepcional oral, se algum profissional de saúde já explicou algo em relação a saúde sexual para eles nas escolas e se eles buscaram alguma informação sobre o assunto.

A partir dos questionários dos adolescentes, as variáveis quantitativas foram categorizadas e registradas em forma de banco de dados no Microsoft Excel. Nesse mesmo software foram realizados testes estatísticos simples, descritivo com frequência absoluta e apresentados na forma tabelas para melhor explicação dos resultados alcançados. 
Cumpriram-se os preceitos éticos da Resolução 466/2012 do Conselho Nacional de Saúde/MS, sendo envidado para Comitê de ética em Pesquisa (CEP) da Faculdade de Ciências Médicas da Paraíba, sendo aprovado no dia 17 de Setembro de 2018 com a CAAE: 95235418.6.0000.5175.

\section{RESULTADOS}

Dos adolescentes participantes, $72,2 \%$ estão na faixa etária entre 13 a 15 anos de idade e $91,6 \%$ declaram ser solteiros. A maioria dos participantes $(63,8 \%)$ cursa o $9^{\mathrm{a}}$ ano, se consideram da cor parda $(75 \%)$ e apenas três dos adolescentes declararam ter filhos. Os dados mostraram que só um adolescente tem outra atividade secular (agricultor), enquanto a maioria referiu como profissão ser estudante. Quanto à renda familiar, percebe-se que 27,7 \% têm por base econômica o incentivo governamental (bolsa família), mas a maior parte dos adolescentes não sabia descrever essa informação $(47,2 \%)$. Dos entrevistados $77,7 \%$ relataram dividir residência com uma até cinco pessoas (Tabela 1). 
Tabela 1 - Distribuição dos dados socioeconômicos dos adolescentes entrevistados. Campina Grande - PB, 2018.

\begin{tabular}{ccc}
\hline VARIÁVEIS & CATEGORIAS & $\%$ \\
Faixa Etária & 13 a 15 & $72,2 \%$ \\
& 16 a 19 & $27,7 \%$ \\
Estado civil & Solteira & $91,6 \%$ \\
& Casada & $2,7 \%$ \\
Escolaridade & União estável & $5,5 \%$ \\
& $8^{\circ}$ ano & $25 \%$ \\
Quantidades de filhos & $9^{\circ}$ ano & $63,8 \%$ \\
& $2^{\circ}$ ano & $11,1 \%$ \\
Cor/ raça & Nenhum & $91,6 \%$ \\
& 1 filho & $8,3 \%$ \\
Profissão & Branca & $25,0 \%$ \\
& Parda & $75,0 \%$ \\
Renda familiar & Estudante & $97,2 \%$ \\
& Agricultor & $2,7 \%$ \\
& Bolsa família & $27,7 \%$ \\
& Até um salario mínimo & $16,6 \%$ \\
Moram com os adolescentes & Mais de um salario mínimo & $8,3 \%$ \\
& 1 a 5 pessoas & $77,7 \%$ \\
& 6 a 10 pessoas & $16,6 \%$ \\
& 10 a 15 pessoas & $2,7 \%$ \\
\hline
\end{tabular}

Fonte: Dados da Pesquisa (2018).

Quando investigado o conhecimento dos adolescentes pesquisados sobre saúde sexual e reprodutiva, uso dos métodos contraceptivos e assistência em saúde foi possível perceber que, dos adolescentes entrevistados $52,7 \%$ já ouviram falar sobre saúde sexual. Contudo, o número de adolescentes que nunca ouviram falar ainda é muito expressivo, apresentando um índice de 47,2\% (Tabela 2).

Da amostra entrevistada neste estudo, 38,8\% relataram que o enfermeiro já explicou algo sobre saúde sexual, mas a maioria $(61,1 \%)$ afirmou que não tiveram nenhuma explicação sobre o tema. Somado a isso, $19,4 \%$ dos adolescentes afirmaram ter vida sexual ativa contra $80,5 \%$ que relataram não ter tido relação sexual ainda. Os adolescentes quando questionados sobre os métodos contraceptivos, a maior parcela $(55,5 \%)$ afirmou saber o que são métodos contraceptivos. Em contrapartida, $44,4 \%$ e os que relataram não saber do que se 
trata, sendo esse um número expressivo. A maioria que relatou saber o que são esses métodos relacionaram a uma forma de prevenção de forma subjetiva (3 participantes), ou ao uso de preservativo (5 participantes), ou a um método hormonal (6 participantes), ou com a idéia de método para evitar gravidez (3 participantes) e somente 3 deles relacionaram com prevenção de doenças e gravidez.

Em sua maioria $(69,4 \%)$ os adolescentes, afirmaram já ter ouvido falar em métodos contraceptivos contra 30,5\% que afirmaram não ter ouvido sobre o tema. Dos adolescentes entrevistados $100 \%$ afirmaram conhecer ou já ter ouvido falar da camisinha, alguns apenas não sabem o significado da palavra métodos contraceptivos e/ou não relacionam com a camisinha. Sobre o uso de pílulas anticoncepcionais, 91,6\% dos entrevistados, falaram que conhecem ou já ouviram falar em pílula anticoncepcional. Esses dados conduzem ao entendimento de que os adolescentes pesquisados estão recebendo informações sobre métodos contraceptivos, mas, não pelos profissionais da saúde, uma vez que poucos afirmaram ter informações sobre saúde sexual pelo enfermeiro, o que pode conduzir a um entendimento errôneo do que são e da forma de usar os métodos contraceptivos.

Tabela 2 Conhecimento dos adolescentes pesquisados sobre vida sexual e métodos contraceptivos. Campina Grande - PB, 2018.

VARIÁVEL

Sabe algo sobre saúde sexual?

Tem Vida sexual ativa

Você Sabe o que são métodos contraceptivos?

Já ouviu falar desses métodos?

Conhece ou já ouviu falar da camisinha?

Já ouviu falar da pílula anticoncepcional

Já fez uso desses métodos

Fonte: Dados da Pesquisa (2018).

\begin{tabular}{cc} 
SIM (\%) & NÃO (\%) \\
$52,7 \%$ & $47,2 \%$ \\
$19,4 \%$ & $80,5 \%$ \\
$55,5 \%$ & $44,4 \%$ \\
$69,4 \%$ & $30,5 \%$ \\
$100,0 \%$ & $0 \%$ \\
$91,6 \%$ & $8,3 \%$ \\
$13,8 \%$ & $86,1 \%$ \\
\hline
\end{tabular}

$\operatorname{SIM}(\%)$

$47,2 \%$

$44,4 \%$

$30,5 \%$

$8,3 \%$

$86,1 \%$

Quando perguntados sobre o uso de algum método contraceptivo, 13,8\% dos adolescentes afirmaram já ter feito uso. Considerando o número de adolescentes que tem vida sexual ativa, o número dos que fazem uso do método ainda é inferior ao esperado. Quando abordado a assistência de saúde sobre a vida sexual dos 
adolescentes pesquisados foi possível perceber que a maior parte dos adolescentes entrevistados $(80,5 \%)$ afirmou ser necessária a presença de algum profissional da saúde abordar a temática com eles e 19,4\% que descreveram não ser necessário (Tabela 3). A maioria mostrou se interessada na presença de profissionais de saúde debatendo sobre saúde sexual e tudo que envolve esse tema.

Os dados dessa pesquisa demonstram que, um número pequeno $(5,5 \%)$ dos adolescentes afirmou já ter procurado alguém da saúde pra buscar informações sobre o assunto e $94,4 \%$ relataram nunca ter procurado esses profissionais.

Tabela 3 - Assistência de saúde na vida sexual dos adolescentes do município de Caturité-PB. Campina Grande - PB, 2018.

\begin{tabular}{|c|c|c|}
\hline VARIÁVEL & $\operatorname{SIM}(\%)$ & NÃO (\%) \\
\hline $\begin{array}{l}\text { Informações sobre saúde sexual nas escolas fornecidas } \\
\text { pelos enfermeiros. }\end{array}$ & $38,8 \%$ & $61,1 \%$ \\
\hline Necessidade da abordagem sobre saúde sexual na escola. & $80,5 \%$ & $19,4 \%$ \\
\hline $\begin{array}{l}\text { Procura pelo profissional da saúde para falar sobre saúde } \\
\text { sexual. }\end{array}$ & $5,5 \%$ & $94,4 \%$ \\
\hline
\end{tabular}

Fonte: Dados da Pesquisa (2018).

\section{DISCUSSÃo}

De acordo com os dados dessa pesquisa a situação socioeconômica dos adolescentes pesquisados é possível perceber uma predominância de uma renda baixa. Segundo Oliveira et al.(2015), a maioria dos adolescentes pesquisados por ele também possuíam baixa renda, ou seja, vivem com apenas um salário mínimo, o que não dá para suas necessidades pessoais. Ele relaciona esse dado com o acesso que eles têm aos métodos contraceptivos, mas a falta de informação necessária para o seu uso e pode ocasionar em consideráveis danos para esse publico. Somado a isso, Hartmann e Cesar, (2013), em seu artigo fala que é importante destacar a população mais pobre como prioritária por apresentarem maior risco do não conhecimento ao preservativo masculino. 
Associado a isso os resultados demonstram que pouco mais da metade da população estudada revela ter conhecimento sobre os métodos contraceptivos. Há indícios de que os adolescentes detêm conhecimento sobre os principais métodos contraceptivos, mas mesmo assim mostram-se descuidados. Por esse motivo as equipes de saúde além de serem incumbidos pela oferta e direção dos métodos contraceptivos devem desenvolver ao lado dos profissionais de educação técnicas e para formação desses adolescentes abrangendo as políticas de saúde mais voltada para saúde sexual e reprodutiva (FERREIRA et al., 2014). Isso porque estudo demonstra que o conhecimento dos adolescentes sobre a temática nos cenários da sua pesquisa se dar de forma igualitária ou seja não há diferença nas escolas publicas ou particular, sendo em ambas deficitário, no passo em que os adolescentes não sabem bem sobre mudanças ligadas ao seu corpo como também sobre ISTs (GUBERT et al., 2016).

Associado a isto está a percepção que os dados desta pesquisa revelam sobre a pouca atuação dos enfermeiros na educação sexual e reprodutiva dos adolescentes. Isso pode ser visto quando a maior parte dos participantes revelou não receber nenhuma explicação sobre a temática. Importa saber que a saúde sexual do adolescente é de responsabilidade da escola e do profissional de saúde. Almeida et al. (2017), destaca a escola como ator importante nesse contexto, uma vez que tem um papel significativo na educação sexual dos alunos, e cita a instituição como corresponsáveis nestes ensinamentos e ainda os profissionais de saúde, como peça fundamental para que haja integralidade na abordagem a sexualidade do adolescente.

Associado a isso Martins et al. (2012), evidenciam a importância de possibilitar aos adolescentes locais para debates e ensinamentos acerca da sexualidade, colocando as questões de crenças e proibições de forma eficiente e recíproca. A prática de oficinas nas escolas de educação sexual por profissionais de saúde e educação proporciona respostas afirmativas em relação a favorecimento de mudanças comportamentais pela troca de experiências no dia a dia entre adolescentes.

Associado a falta de informação por parte dos profissionais da saúde está o risco aumentado para contágio de IST`s e gravidez indesejadas uma vez que 
parcela da população estudada já iniciou sua vida sexual. Para Molina et al.(2015), em sua pesquisa mostrou que adolescentes vem iniciando sua vida sexual mais cedo em ambos os sexos. Apesar disso, estão vulneráveis, uma vez que não sabem o que é saúde sexual. Silva et al. (2015), descreve que o inicio da vida sexual para sua amostra é precoce e o não uso de preservativos leva os mesmos a um comportamento de risco para contrair ISTs, HIV e gravidez na adolescência.

Isso porque como demonstrado nos dados dessa pesquisa os adolescentes $(44,4 \%)$ não sabem o que são métodos contraceptivos. Para Campos et al. (2016), os adolescentes sabem o que são métodos contraceptivos mais relacionam a apenas preservativo masculino e pílula anticoncepcional, ele ainda diz que os adolescentes já ouviram falar em outros métodos mas, em sua maioria, acham estranhos.

Em seu estudo Madureira, Marques e Jardim (2010),falam que as adolescentes acham que seu conhecimento sobre métodos contraceptivos é apropriado, mas eles mostram que se resume a camisinha masculina e feminina, pílula do dia seguinte e o anticoncepcional oral, mostrando ser insuficiente esse conhecimento sobre outros métodos também. Ele ainda mostra que os adolescentes têm dúvidas sobre sua função seguridade e efetividade desses métodos, mostrando a necessidade de sempre ter diálogos com essa faixa etária.

Benincasa, Resende e Coniaric (2008), diz em seus estudos que os adolescentes têm informações sobre prevenção só que a maioria dessas informações são incorretas. Foi mostrado que eles sabem as consequências de ter relação sem proteção, mas acham que não vai acontecer com eles e citam a necessidade de alguém de confiança para conversar sobre o assunto.

Em sua pesquisa, Silva et. al. (2016) falam que a maioria da sua amostra tem conhecimento sobre alguns contraceptivos e também mostra que os mais conhecidos são camisinha feminina /masculina e anticoncepcional oral e injetável. Somado a isto e corroborando com esta pesquisa Campos et al. (2016) achou resultados similares quando mostra que $100 \%$ dos adolescentes entrevistados conhecem o preservativo masculino (camisinha) e relacionaram como o método mais familiar e mais eficaz comprovando que, sua utilização já foi bem divulgada. 
Segundo Abtibol et al. (2015), seu estudo mostra que todos os adolescentes da sua pesquisa conhecem o preservativo como método contraceptivo, mas prevalece o não conhecimento do seu uso, eles também desconhecem a utilização de outros método, com isso se faz necessário que a educação sexual seja passada de forma onde participem escola, família e unidade de saúde afim de que esses conhecimentos se transformem em ações efetivas.

É relevante destacar que os adolescentes pesquisados afirmam conhecer as pílulas anticoncepcionais e o preservativo masculino, mas não pelo profissional de saúde. Araújo et.al. (2015), em sua pesquisa diz que, por os adolescentes estarem iniciando sua vida sexual cada vez mais cedo isso contribui para que eles tenham conhecimento sobre anticoncepcionais mais cedo também. Apesar disso, Molina et al.(2015) destaca que os adolescentes têm informações e indicações sobre métodos contraceptivos através de vizinho ou amigos o que leva a conhecimento e utilização desses métodos de forma deficitária e errônea.

A partir dos dados dessa pesquisa há indícios de que a menor parte da população estudada utiliza os métodos contraceptivos, uma vez que tem-se uma parcela de adolescentes que tem sua sexualidade ativa mas poucos que fazem uso dos métodos. Sobre isso, Costa Guerra e Araújo, (2016), explicam que, em sua pesquisa, a minoria dos adolescentes, mesmo com vida sexual ativa, nunca usou qualquer método contraceptivo contra a maioria que relataram ter vida sexual ativa e fazer uso de preservativo.

Silva, Jacob e Hirdes (2015), acrescenta que a partir das análises em sua pesquisa foi possível perceber que os adolescentes tem o conhecimento sobre HIV/ISTs, e que ISTs são adquiridas na relação sexual e que umas não tem cura. Além disso, os adolescentes demonstram relacionar a camisinha como meio de proteção.

Os adolescentes pesquisados reconhecem a importância da assistência de saúde na educação sexual e reprodutiva. O ambiente propício para essa abordagem é a escola e a família. Segundo Cesário Costa e Pereira, (2014), é importante a presença do enfermeiro nas escolas através do PSE, uma vez que se refere ao melhoramento da qualidade de vidas dos adolescentes. Para Higarashi et al. (2011), é possível inserir na atuação do enfermeiro algumas preferências para intermédio na 
educação e assistência ao adolescente, como prevenção das doenças e promoção da saúde no que se refere a sexualidade.

Luna et al.(2012), traz que o enfermeiro ao fazer ações de educação em saúde sobre DSTs/AIDS, deve produzir técnicas que levem o adolescente a se familiarizar com os modos de prevenção das mesmas para que tenha sua sexualidade desenvolvida de forma saudável.

A escola passa a ser o local mais prático para atuar na prevenção de doenças e de gravidez indesejada em adolescentes uma vez que os dados dessa pesquisa demonstram que o adolescente não tem o hábito de freqüentar a unidade de assistência à saúde.

Em seus estudos, Vieira et al.(2014), mostrou que os adolescentes não enxergam a ESF como efeito para contribuição para promoção da sua saúde, o que mostra uma presença não concreta.

No estudo de Santos e Ressel (2013), declaram que a busca dos adolescentes ao serviço de saúde é pelas sequentes causas: uso de preservativo, consulta de pré-natal, busca por anticoncepcional e teste de gravidez.

Em seu estudo Rocha et al. (2012), diz que os adolescentes só procuram o posto de saúde quando estão doentes e tem algumas dificuldades na buscar a unidade como, falta de tempo, demora no atendimento, ausência dos pais na consulta e o mal atendimento, uma vez que se deve buscar por novas praticas e estratégias para inserção deste publico na unidade de saúde, e buscar de novos meios teóricos e prático para que se possa melhorar a equipe de saúde em prol dos adolescentes.

Assim, atuar na atenção à saúde do adolescente demonstra ser uma ação que pode representar um impacto positivo e minimizar os danos causados pela iniciação sexual precoce, uma vez que, a vida sexual deve ser permeada de conhecimento sobre métodos contraceptivos por parte do enfermeiro e em parceria com as escolas. 


\section{CONCLUSÃO}

Os adolescentes da pesquisa mostraram saber os que são métodos contraceptivos, os principais deles, mas de forma incompleta e errônea, pois não relacionam camisinha e anticoncepcional com esses métodos, isso mostra o déficit na coparticipação entre saúde e educação. Eles estão iniciando sua vida sexual muito cedo sem instruções, ou com pouca instrução, onde pode levar a se contrair com alguma ISTs ou até mesmo ter uma gravidez indesejada e com total despreparo para tal responsabilidade.

É possível entender que os adolescentes desejam conhecer mais sobre a temática e que aprovam a assistência de saúde nas escolas para ajudá-los a compreender a melhor forma de uso e esclarecimento dos métodos contraceptivos.

O enfermeiro demonstra ser o profissional de pode incluir na assistência de saúde aos adolescentes ações que visem a educação sexual e reprodutiva para os adolescentes, uma vez que, estão iniciando sua vida sexual e em processo adaptativo de desenvolvimento físico, intelectual e emocional.

A partir dos dados dessa pesquisa os enfermeiros podem traçar metas voltadas para esse público junto com o sistema educacional, através do PSE, e também dentro de suas unidades de saúde buscando por uma assistência voltada para eles de forma completa, conquistando e respeitando o adolescente em seu mundo de dúvidas e angústias. 


\section{REFERÊNCIAS BIBLIOGRÁFICAS}

ABTIBOL, C. S. et al. Conhecimento dos adolescentes de uma escola pública sobre métodos contraceptivos. Revista Interdisciplinar, Cajazeiras, v. 8, n. 2, p. 94-100, 2015. Disponível em: https://revistainterdisciplinar.uninovafapi.edu.br/index.php/revinter/article/viewFile/580/pdf 225. Acesso em: 6 mar. 2018.

ALMEIDA, R. A. A. S. et al. Knowledgeof Conhecimento de adolescentes relacionados às doenças sexualmente transmissíveis e gravidez,RevBrasEnferm, [s.I], v. 70, n. 5, p. 10871094, 2017. Disponivel em: http://www.scielo.br/scielo.php?pid=S003471672017000501033\&script=sci_arttext\&tlng=pt. Acesso em: 17 nov. 2018.

ALVES, A.; ALBINO, A. T.; ZAMPIERE, M. F. M. Um olhar das adolescentes sobre as mudanças na gravidez: promovendo à saúde mental na atenção básica. Reme Revista Mineira de Enfermagem, [s.I],v. 15, n. 4, p. 545-555, 2011. Disponível em: www.reme.org.br/exportarpdf/69/v15n4a11.pdf.Acesso em: 6 mar. 2018.

ARAÚJO, A. K. L.et al. Contracepção na adolescência: conhecimento, métodos escolhidos e critérios adotados. Revista de Pesquisa Cuidado é Fundamental Online, Rio de Janeiro,v. 7, n. 3, p. 2815-2825, 2015. Disponível em: www.redalyc.org/articulo.oa?id=505750947037. Acesso em: 17 nov. 2018.

BENINCASA, M.; REZENDE, M. M.; CONIARIC, J. Sexo desprotegido e adolescência: fatores de risco e de proteção. Psicologia: Teoria e Prática, São Paulo, v. 10, n. 2, p. 121- 134, 2008. Disponível em: pepsic.bvsalud.org/scielo.php?script=sci_arttext\&pid=S1516. Acesso em: 17 nov. 2018.

BRASIL.Planalto do governo. Lei $n^{\circ} 8.069$, de 13 de julho de 1990.Disponível em:http://www.planalto.gov.br/ccivil_03/LEIS/L8069.htm. Acesso em: 24 ago. 2018.

BRASIL. Ministério da Saúde. Proteger e cuidar da saúde de adolescentes na atenção básica, $2003 . \quad$ Disponível em: http://bvsms.saude.gov.br/bvs/publicacoes/proteger_cuidar_adolescentes_atencao_basica.pdf. Acesso em: 22 set. 2018.

BRASIL. Planalto do governo.Decreto n $^{\circ}$ 6.286, de 5 de dezembro de 2007.. Disponível em: /www.planalto.gov.br/ccivil_03/_ato2007-2010/2007/decreto/d6286.htm. Acesso em:6abr. 2018.

CAMPOS, H. M.et.al. Saúde sexual, gênero e percepções de adolescentes sobre o preservativo feminino. Adolesc. Saude, Rio de Janeiro, v. 13, n. 2, p. 26-32, 2016. Disponível em: http://www.adolescenciaesaude.com/detalhe_artigo.asp?id=58. Acesso em: 18 nov. 2018.

CESARIO, N. C. M.; COSTA, R. J. V.; PEREIRA, J. T. O enfermeiro no ambiente escolar: práticas educativas atuais e eficazes. Revista Tecer, Belo Horizonte, v. 7, n. 12, 2014. Disponível em: https://www.metodista.br/revistas/revistas- izabela/index.php/tec/article/view/345. Acesso em: 17 de nov. 2018. Acesso em: 18 nov. 2018.

COSTA, G. P. O.; GUERA, A. Q. S.; ARAUJO, A. C. P. F. Conhecimentos, atitudes e práticas sobre contracepção para adolescentes. Revista de pesquisa cuidado é fundamental online, Rio de Janeiro, v. 8, n. 1, p. 3597-36083, 2016. Disponível em: bases.bireme.br/cgibin/wxislind.exe/iah/online/?IsisScript=iah. Acesso em: 17 nov. 2018.

DIAS, E. G.et al. Conhecimento e comportamento dos adolescentes de uma escola publica sobre sexualidade e métodos contraceptivos. Revista Baiana de Saúde Publica, Bahia, v. 41, n. 1, p.120-130, 2017. Disponível em https://issuu.com/rbspsesab/docs/revista_v41_n1_2017. 
Acesso em: 18 de maio de 2018.

FILIPINI, C. B.et al. Transformações físicas e psíquicas: um olhar do adolescente.Adolescência \& Saúde, Rio de janeiro, v. 10, n. 1,p.22-29,2013. Disponível em: http://www.adolescenciaesaude.com/detalhe_artigo.asp?id=351\#.Acesso em: 6 mar. 2018.

FERREIRA, E. B. et al. Causas predisponentes à gestação entre adolescentes. Rev. fundam. Care, Rio de janeiro, v. 6, n. 4, p. 1571-1579, 2014.

GUBERT, F. A. M.et al.Perfi I sociodemográfico e sexual de adolescentes escolares sexualmente ativas em Fortaleza-CE,Adolesc. Saude, Rio de Janeiro, v. 13, v. 2, p. 41-50, 2016. Disponível em: $w w w$.adolescenciaesaude.com/detalhe_artigo.asp?id=583. Acesso em: 16 nov. 2018.

HARTMANN, J. M.; CESAR, J. A. Conhecimento de preservativo masculino entre adolescentes: estudo de base populacional no semiárido nordestin. Cad. Saúde Pública, Rio de Janeiro, v. 29, n. 11, p. 2297-2306, 2013. Disponível em: www.scielo.br/pdf/csp/v29n11/16.pdf . Acesso em: 10 nov. 2018.

HIGARASHI, I. H. et al. Ações desenvolvidas pelo enfermeiro junto aos adolescentes no programa saúde da família em Maringá/Paraná,Rev Rene, Fortaleza, v. 12, n. 1, p. 127-135, 2011. Disponível em: www.periodicos.ufc.br/rene/article/download/4168/323. Acesso em:17 nov. 2018.

LUNA, I. T. C.et al. Ações educativas desenvolvidas por enfermeiros brasileiros com adolescentes vulneráveis às DST/AIDS. Ciencia y Enfermeria XVIII, [s.], v. 1, n.2, 2012. Disponível em: https://scielo.conicyt.cl/pdf/cienf/v18n1/art_05.pdf. Acesso em: 18 nov. 2018.

MADUREIRA, L.; MAEQUES, I. R.; JARDIM, D. P. J. Contracepção na adolescência: conhecimento e uso,CogitareEnferm, Curitiba, v. 15, n. 1, p. 100-105, 2010. Disponível em: https://revistas.ufpr.br/cogitare/article/view/17179. Acesso em: 10 nov, 2018.

MARTINS, C. B. de G.et al. Sexualidade na adolescência: mitos e tabus. Ciencia y Enfermeria

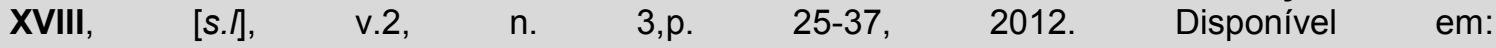
https://scielo.conicyt.cl/scielo.php?script=sci_abstract\&pid=S0717...Ing. Acesso em: 10 nov. 2018.

MOLINA, M. C. C.et al. Conhecimento de adolescentes do ensino médio quanto aos métodos contraceptivos. O Mundo da Saúde, São Paulo, v. 39, n. 1, p.22-31, 2015. Disponível em: bvsms.saude.gov.br/bvs/periodicos/mundo.../Conhecimento_adolescentes_ensino.pdf. Acesso em: 16 nov. 2018.

ROCHA, F. A. A. et al. Programa de Saúde da Família: percepção de adolescentes de um município do Estado do Ceará. Adolesc. Saude, Rio de Janeiro, v. 9, n. 2, p. 7-13, 2012. Disponível em: www.adolescenciaesaude.com/detalhe_artigo.asp?id=310. Acesso em: 10 nov. 2018.

RODRIGUES, M. P. et al. Percepção sobre os efeitos psicossociais da gravidez na adolescência no cenário da estratégia e saúde da família. Revista Ciência Plural, [s.I], v. 1, n. 3, p. 81-97, 2017. Disponível em: http://docplayer.com.br/58913845-Percepcoes-sobre-osefeitos-psicossociais-da-gravidez-na-adolescencia-no-cenario-da-estrategia-saude-dafamilia.html. Acesso em: 6 mai. 2018.

SANTOS, C. C.; RESSEL, L. B. O adolescente no serviço de saúde. Adolesc. Saude, Rio de Janeiro, v. 10, n. 1, p. 53-55, 2013.2 Disponível em:www.adolescenciaesaude.com/detalhe_artigo.asp?id=355. Acesso em: 10 nov. 2018.

SILVA, A.S. N.et al. Início da vida sexual em adolescentes escolares: um 
estudo transversal sobre comportamento sexual de risco em Abaetetuba. Brasil. RevPan-

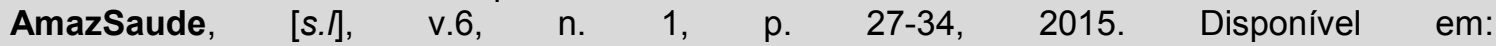
http://scielo.iec.gov.br/scielo.php?script=sci_arttext\&pid=\$2176-62232015000300004. Acesso em:10 nov. 2018.

SILVA, A. T.; JACOB, M. H. V. M.; HIRDIS, A. A; Conhecimento de adolescentes do ensino médio sobre DST/AIDS no sul do Brasil. Aletheia, [s.], v.2, n. 46, 2015. Disponível em: pepsic.bvsalud.org/scielo.php?script=sci_arttext\&pid=S1413. Acesso em: 9 nov. 2018.

SILVA, C. S. O.et al. O adolescente na Estratégia Saúde da Família: uma revisão integrativa de literatura. AdolescSaude, Rio de Janeiro, v. 13, n. 3, p. 76-87, 2016. Disponível em: http://www.adolescenciaesaude.com/detalhe_artigo.asp?id=609\#. Acesso em: 24 ago. 2018.

OLIVEIRA, R. N.et al. Iniciação sexual de adolescentes e conhecimento dos métodos contraceptivos. Rev. Ciênc. Saúde Nova Esperança, [s.I], v. 13, n. 2, p. 66-76, 2015. Disponível em:www.facene.com.br/wp-content/uploads/2010/11//nicia-. Acesso em: 18 de nov. 2018.

SANTOS, D.etal. Sexualidade na adolescência: contaminação de IST's. In: CONGRESSO INTERNACIONAL DE ENFERMAGEM, 12, 2017, São Paulo, Anais... São Paulo: CIE, 2017, P.1-2.

VIEIRA, R. P.et al. Participação de adolescentes na Estratégia Saúde da Família a partir da Estrutura Teórico-Metodológica de uma Participação Habilitadora. Rev. Latino- Am Enfermagem, [s.I], v. 2 n. 2, p. 309-316, 2014. Disponível em: www.scielo.br/pdf/rlae/v22n2/pt_0104-1169-rlae-22-02-00309.pdf. Acesso em:16 nov. 2018.

DETALHAR PROJETO DE PESQUISA

- DADOS DA VERSÄO DO PROJETO DE PESQUISA
Titulo da Pesquisa: CONHECIMENTO DOS ADOLESCENTES SOBRE MÉTODOS CONTRACEPTIVOS E ASSISTÊNCIA EM SAÚDE.
Pesquisador Responsável: Larissa Soares Mariz Vilar de Miranda
Área Temática:
Versäo: 2
CAAE: 95235418.6 .0000 .5175
Submetido em: $17 / 09 / 2018$
Instituiçäo Proponente: Faculdade de Ciênncias Médicas de Campina Grande
Situação da Versão do Projeto: Aprovado
Localizaçäo atual da Versão do Projeto: Pesquisador Responsável
Patrocinador Principal: Financiamento Próprio

